\title{
Survival Probabilities Related to Histology, Grade and Stage in Patients With Salivary Gland Tumors
}

\author{
YAIR ISRAEL $^{1 *}$, ADI RACHMIEL ${ }^{1 *}$, KONSTANTIN GOUREVICH $^{2}$ and RAFAEL NAGLER ${ }^{1}$ \\ ${ }^{1}$ Department of Oral and Maxillofacial Surgery, Faculty of Medicine, Rappaport Family Institute for \\ Research in the Medical Sciences, Technion - Israel Institute of Technology, Haifa, Israel; \\ ${ }^{2}$ Department of Nuclear Medicine Rambam Medical Center, Faculty of Medicine, Rappaport Family \\ Institute for Research in the Medical Sciences, Technion-Israel Institute of Technology, Haifa, Israel
}

\begin{abstract}
Background: The diversity of malignant salivary gland tumors challenges the study of survival rates. The current study evaluated patient survival rates using KaplanMeier analysis and examined the relative effects of histology, grade and stage on survival. Materials and Methods: Using the Kaplan-Meier model, cancer-specific (CSS) and diseasefree (DFS) survival probabilities were calculated as a function of time. Results: Of 101 patients, 79 survived and 22 died of their disease. The probability of CSS was 0.83, 0.73 and 0.61 at 5, 10 and 15 years, respectively; corresponding probability of DFS was 0.69, 0.59 and 0.54, respectively. Conclusion: CSS and the DFS probabilities in patients with salivary malignancies were quite high at 5 years, although these rates dropped over the long-term; the lethal effect of the malignancy is often delayed and prolonged. Tumor histology, grade and stage are well established factors in predicting prognosis. Although the subgroups of patients with MECA and SCC were too small to allow adequate statistical analysis, clear tendencies for devastating effects of poor differentiation in SCC and higher grade in MECA were shown. That is, 2/4 patients with highgrade MECA died from their disease, while only 1/15 with low-intermediate grade MECA died from their disease. Similarly, 2/4 patients with poorly differentiated SCC died from their disease, while only 1/5 with well-to-moderatelydifferentiated SCC died from their disease. Factors such as
\end{abstract}

\footnotetext{
*These Authors contributed equally to this study.

Correspondence to: Prof. R. Nagler, Department of Oral and Maxillofacial Surgery, Rambam Medical Center and Faculty of Medicine, Rappaport Family Institute for Research in the Medical Sciences, Technion-Israel Institute of Technology, Haifa 31096 , Israel. Tel: +972 77886687, Fax: +972 46541295, e-mail: nagler@tx.technion.ac.il
}

Key Words: Salivary tumors, survival, stage, grade, histology. molecular markers should be further studied in an effort to improve prognosis prediction.

The diversity of malignant salivary gland tumors in their histopathology and in a variety of other characteristics challenges the study of survival rates and treatment outcomes. Many studies over the years have reported variable rates of overall (1-3) and disease-free (DFS) (4-6) survival for patients with malignant salivary gland tumors.

Assessment of prognostic factors in salivary gland cancer is difficult, since these tumors are characterized by a low incidence and an enormous morphological heterogeneity with different clinical courses. Subtypes such as acinic cell carcinomas or polymorphous low-grade adenocarcinomas present an excellent prognosis with a 5-year survival of about $75-100 \%$ (7). Rare subtypes such as salivary duct carcinomas or undifferentiated carcinomas are associated with low 5-year survival rates of about $20-50 \%$ (8).

However, in spite of the numerous studies published concerning the factors affecting the prognosis of patients with salivary tumors, including various molecular aberrations which have been suggested to compromise prognosis (9-15), the topic is still controversial and far from well established. Aside from histological type, often mentioned prognostic factors include: age, stage, grade, gender, pain level, skin and soft-tissue infiltration, facial nerve involvement, perineural growth, resection status and comorbidities (16-19). Prognosis of salivary gland cancer in children and adolescents is much more favorable than in adults. The 5-year overall survival rate for children after curative surgery is about $95 \%$ compared to $60 \%$ for adults $(20,21)$. This is probably due to moderate tumor growth with well-differentiated histology, absence of extension into adjacent tissues and lower frequency of neck node metastasis, although positive lymph nodes are reported in $10-30 \%(20,21)$.

A review published by Jeannon et al. in 2009 showed the clear correlation among advanced tumor size, high-grade histopathology and poor prognosis (with only $35 \%$ overall 
Table I. Prevalence of tumor by type in patients who died from their disease and those who survived.

\begin{tabular}{|c|c|c|c|}
\hline Tumor type & Died $(\mathrm{N}=22), \mathrm{n}(\%)$ & Survived $(\mathrm{N}=79), \mathrm{n}(\%)$ & Total $(\mathrm{N}=101), \mathrm{n}$ \\
\hline \multicolumn{4}{|l|}{ All tumors (\%) } \\
\hline MECA (all grades) & $6(27.3)$ & $22(27.8)$ & 28 \\
\hline ACC & $8(36.4)$ & $17(21.5)$ & 25 \\
\hline SCC (all) & $4(18.3)$ & $6(7.6)$ & 10 \\
\hline PLGA & $1(4.6)$ & $8(10.1)$ & 9 \\
\hline Acinic cell carcinoma & $1(4.6)$ & $6(7.6)$ & 7 \\
\hline Adenocarcinoma NOS & $1(4.6)$ & $5(6.3)$ & 6 \\
\hline Basal cell adenocarcinoma & 0 & $1(1.3)$ & 1 \\
\hline Cribriform cystic adenocarcinoma* & 0 & $1(1.3)$ & 1 \\
\hline Salivary duct carcinoma & 0 & $2(2.5)$ & 2 \\
\hline Carcinoma ex PA & $1(4.6)$ & $4(5.1)$ & 5 \\
\hline $\mathrm{PA}^{\#}$ & 0 & $4(5.1)$ & 4 \\
\hline Ep. myoepithelial carcinoma & 0 & $1(1.3)$ & 1 \\
\hline Myoepithelial carcinoma & 0 & $2(2.5)$ & 2 \\
\hline \multicolumn{4}{|l|}{ MECA } \\
\hline Non specified & $3(13.6)$ & $5(6.3)$ & 8 \\
\hline Low grade & 0 & $6(7.6)$ & 6 \\
\hline Intermediate grade & $1(4.6)$ & $8(10.1)$ & 9 \\
\hline High grade & $2(9.1)$ & $2(2.5)$ & 4 \\
\hline Intra-osseous & 0 & $1(1.3)$ & 1 \\
\hline \multicolumn{4}{|l|}{ SCC } \\
\hline Non specified & $1(4.6)$ & 0 & 1 \\
\hline Poorly differentiated & $2(9.1)$ & $2(2.5)$ & 4 \\
\hline Moderately differentiated & 0 & $1(1.3)$ & 1 \\
\hline Well differentiated & $1(4.6)$ & $3(3.4)$ & 4 \\
\hline
\end{tabular}

ACC: Adenoid cystic carcinoma; PA: pleomorphic adenoma; NOS: not otherwise specified; SCC: squamous cell carcinoma; MECA: mucoepidermoid carcinoma; PLGA: polymorphous low-grade adenocarcinoma; *low grade; ${ }^{\#}$ with squamous metaplasia.

survival rate) in patients with parotid malignant tumors (22). Spiro et al. showed in 2001 how the clinical stage in general and tumor size in particular highly influence prognosis and survival (23). Furthermore, tumor size was suggested by Speight et al. to be a critical predictive factor, more important than histopathological grade (24). Speight's group introduced their ' $4 \mathrm{~cm}$ rule' to the professional world - claiming that stage III and IV tumors which are larger than $4 \mathrm{~cm}$ in diameter will always have a worse prognosis, regardless of their histopathological type and regardless of the existence of neck metastasis (24). They maintained that malignant tumors larger than $4 \mathrm{~cm}$ in diameter are considered an absolute indication for administration of postoperative adjuvant radiotherapy, and also that the tumor size (specifically T3 and T4 tumors) is considered an independent prognostic factor with negative impact on survival (25-27). According to the results published in 2011 by the Danish Head and Neck Cancer Group, diseasespecific survival rate decreases dramatically for patients diagnosed with $\mathrm{T} 3$ and $\mathrm{T} 4$ tumors, and recurrence rates are significantly increased in these patients (28).

The purpose of the current study was to evaluate the survival rates of patients with different salivary malignancies using Kaplan-Meier analysis and to examine the relative effect that histology, grade and stage have on survival.

\section{Materials and Methods}

In the current study, we analyzed data for all 101 consecutive patients who received definitive therapy for malignant salivary gland tumors at Rambam Medical Center in Haifa, Israel. We did not exclude any patient who was diagnosed with malignant salivary gland cancer. This study was a retrospective one involving patient records. Since the patients were not directly involved and it would not be possible to identify any from the data in this article, approval from the Institutional Ethics Committee and informed-consent forms were not necessary

Statistical evaluation and Kaplan-Meier survival analysis. The statistical analysis was performed using STATA 12.0 software (Stata Corp LLC, TX, USA).

The various categorical variables, numbers and percentages were calculated. The distributions for the categorical variables between the two study groups (the surviving patients as compared to the patients who died due to their disease), were compared and analyzed by the chi-square test (a parametric test) or by Fisher-Irwin exact test (a non-parametric test for small numbers). The Kaplan-Meier model was used to calculate the probability of cancer-specific survival (CSS) and the probability of DFS as a function of time. The differences between the Kaplan-Meier survival curves were tested for significance by the log-rank test.

All statistical tests were analyzed to a significance level of 0.05 . 


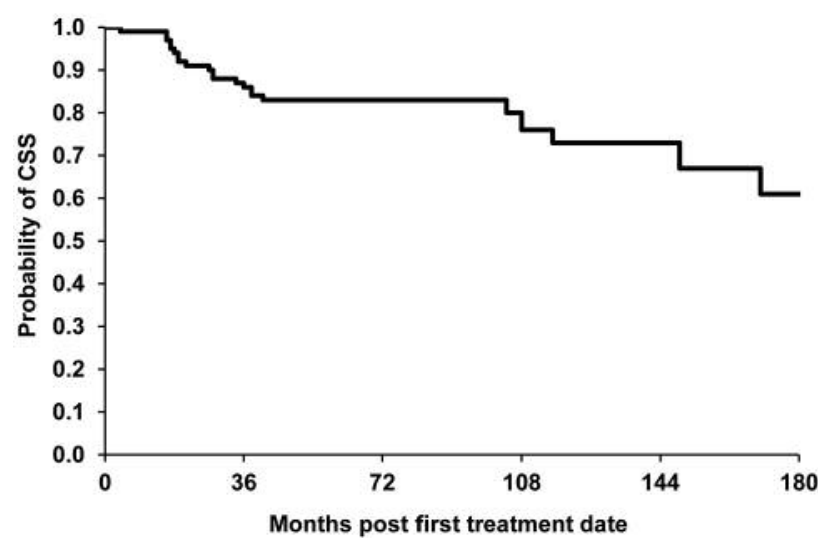

Figure 1. Probability of cancer-specific survival (CSS) of all study patients with primary salivary tumor. Median survival was 206 months.

\section{Results}

Patients, prevalence of tumors, grade and stage. In the current study, we analyzed data for 101 patients who received definitive therapy for malignant salivary gland tumors at Rambam Medical Center in Haifa, Israel. Of the 101, 79 survived and 22 died due to their disease (Table I). These patients were followed-up for up to 15 years post therapy whenever possible.

The most prevalent group was mucoepidermoid carcinoma (MECA) with 28 patients, followed by adenoid cystic carcinoma, squamous cell carcinoma (SCC), polymorphous low-grade adenocarcinoma, acinic cell carcinoma and adenocarcinoma groups. These six groups of salivary malignancies were responsible for 85 of the patients. The other 16 patients belonged to one of the other seven tumor categories (including 1-5 patients in each group), as shown in Table I. Of these smaller groups, the carcinoma ex pleomorphic group was the most prevalent one, with five patients, while other groups such as basal cell adenocarcinoma and cribriform cystic adenocarcinoma were rather rare, with only one patient each (Table I).

Two of the most prevalent tumor groups, the MECA and the SCC groups were further divided into subgroups according to the histological grade or level of differentiation (Table I).

Further division of each histological group into patients who survived the disease following adequate therapy and those who died of their disease revealed no statistical difference in the distribution as related to the specific tumor type involved. For example, $27.3 \%$ of patients who died from their disease had MECA and an almost identical percentage, $27.8 \%$, of those who survived also had MECA (Table I). Of note is the observation that the distribution of major malignant salivary gland tumors in the current study

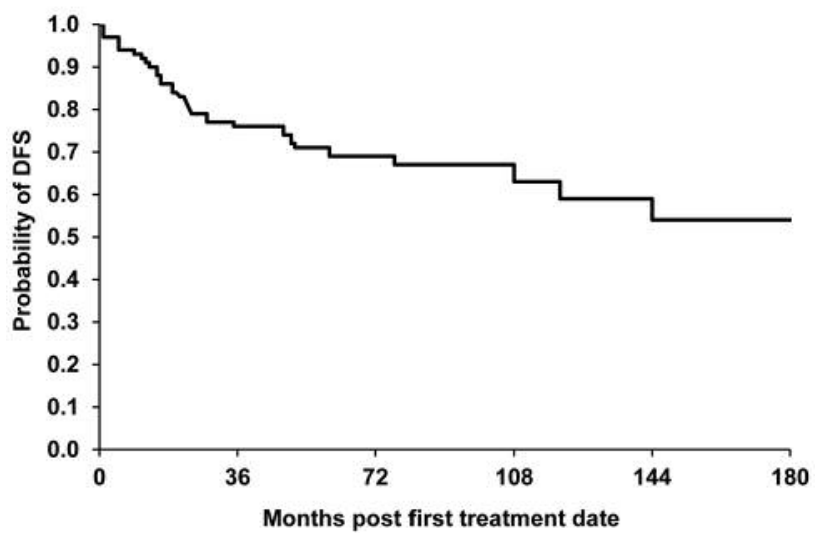

Figure 2. Probability of disease-free survival (DFS) of all study patients with primary salivary tumors. Median survival not calculable.

was similar to and typical of other previously published reports $(29,30)$.

The probability of CSS of all patients with salivary malignant tumors. The probability of CSS at 5 years was 0.83 [95\% confidence intervaI $(\mathrm{CI})=0.73-0.89])$, at 10 years it was $0.73(95 \% \mathrm{CI}=0.57-0.83)$ and at 15 years it was 0.61 (95\% CI=0.41-0.77) (Figure 1).

The probability of DFS of patients with malignant salivary gland tumors. The probability of DFS at 5 years was 0.69 (95\% CI $=0.58-0.78)$, at 10 years it was $0.59(95 \% \mathrm{CI}=0.44-$ $0.71)$, and at 15 years it was $0.54(95 \% \mathrm{CI}=0.37-0.68)$ (Figure 2).

The probability of CSS of patients with MECA. The probability of CSS at 5 years was $0.81(95 \% \mathrm{CI}=0.56-0.93)$, at 10 years it was $0.68(95 \% \mathrm{CI}=0.32-0.87)$ and at 15 years it was $0.68(95 \% \mathrm{CI}=0.32-0.87)$ (Figure 3$)$.

The probability of CSS of patients with adenoid cystic carcinoma. The probability of CSS at 5 years was $0.67(95 \%$ $\mathrm{CI}=0.42-0.83)$, at 10 years it was $0.67(95 \% \mathrm{CI}=0.42-0.83)$ and at 15 years it was 0.45 (95\% CI=0.10-0.76) (Figure 4).

The probability of CSS of patients with SCC. There were 10 patients with SCC who lived 3 months to 12.4 years. The probability of CSS at 5 years was 0.63 (95\% $\mathrm{CI}=0.24-0.87)$, at 10 years it was $0.63(95 \% \mathrm{CI}=0.24-0.87)$ and at 15 years it was 0 (Figure 5).

The probability of CSS of patients with polymorphous lowgrade adenocarcinoma (PLGA). There were nine patients with PLGA tumor type who lived 59 to 178 months. The 


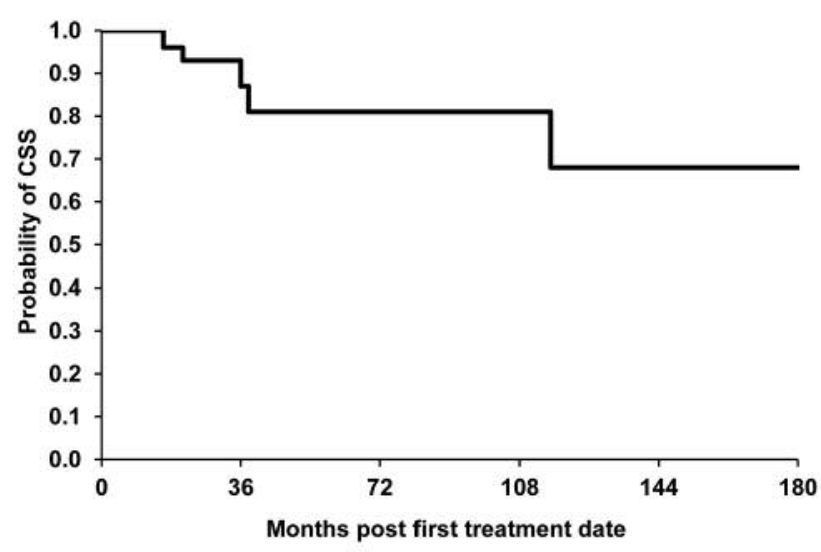

Figure 3. Probability of cancer-specific survival (CSS) of patients with mucoepidermoid adenocarcinoma. Median survival not calculable.

probability of CSS at 5 years was 1.00 , at 10 years it was $0.83(95 \% \mathrm{CI}=0.27-0.97)$ and at 15 years it was $0.83(95 \%$ $\mathrm{CI}=0.27-0.97$ ) (Figure 6).

Although the subgroups of patients with MECA and SCC were too small to allow adequate statistical analysis, clear tendencies for devastating effects of poor differentiation in SCC and higher grade in MECA were shown. That is, 2/4 patients with high-grade MECA died from their disease, while only $1 / 15$ with low-intermediate grade MECA died from the disease. Similarly, $2 / 4$ patients with poorly differentiated SCC died from their disease, while only $1 / 5$ with well-to moderately differentiated SCC died from the disease (Table I).

\section{Discussion}

The overall rates for DFS and CSS rates that we report here are quite in agreement with previous reports, i.e. at 60 months they were $0.69 \%$ and $0.83 \%$ respectively and at 180 months they were $0.54 \%$ and $0.61 \%$ respectively:

Bell et al. showed disease-free survival rates and locoregional control rate at 5 years of $77 \%$ and $86 \%$, respectively. Stage, grade, cervical lymph node metastasis and age were found to make a statistically significant contribution to outcome. They showed that neither site, presence of positive margins nor perineural invasion had a significant impact on survival. Bell et al. concluded that the treatment of salivary gland malignancies remains primarily surgical, although adjunctive radiotherapy may play an important role in patients with advanced-stage disease (31).

The role of chemotherapy in the management of patients with salivary gland cancer is evolving. Various chemotherapeutic regimens are currently used for palliation of advancedstage tumors. Yet there is no demonstrated benefit in the

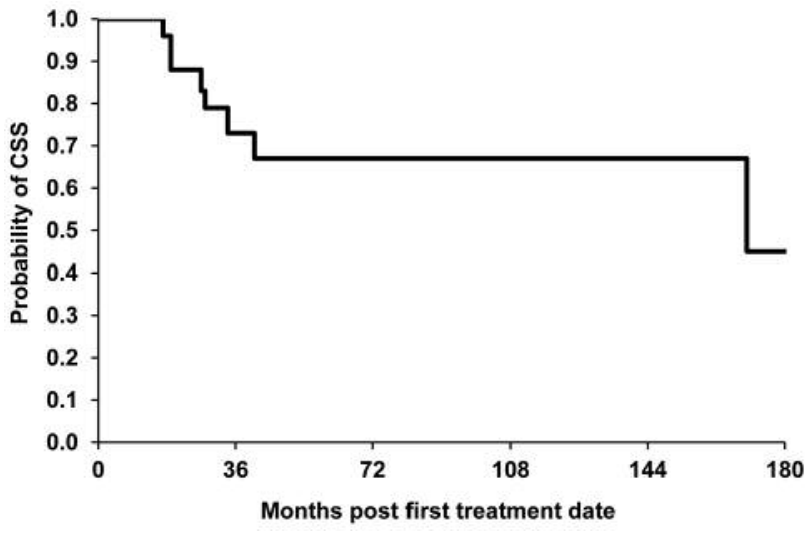

Figure 4. Probability of cancer-specific survival (CSS) of patients with adenoid cystic carcinoma. Median survival was 170 months.

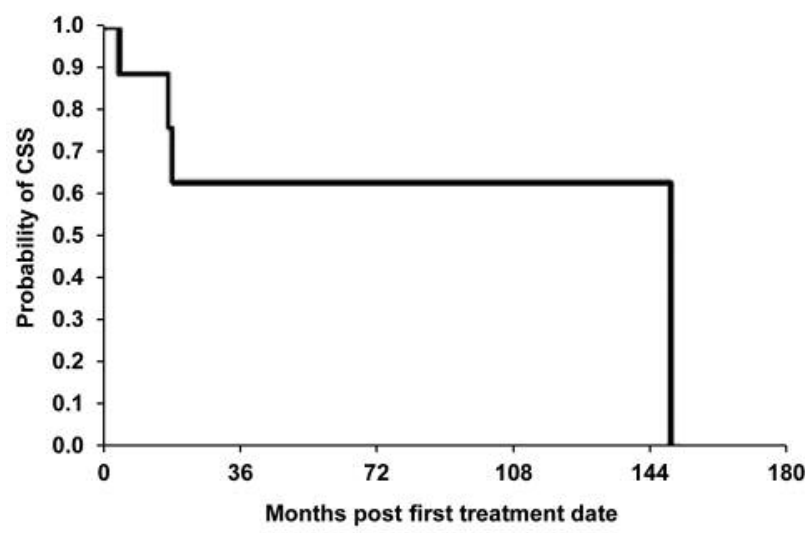

Figure 5. Probability of cancer-specific survival (CSS) of patients with squamous cell carcinoma. Median survival was 149 months.

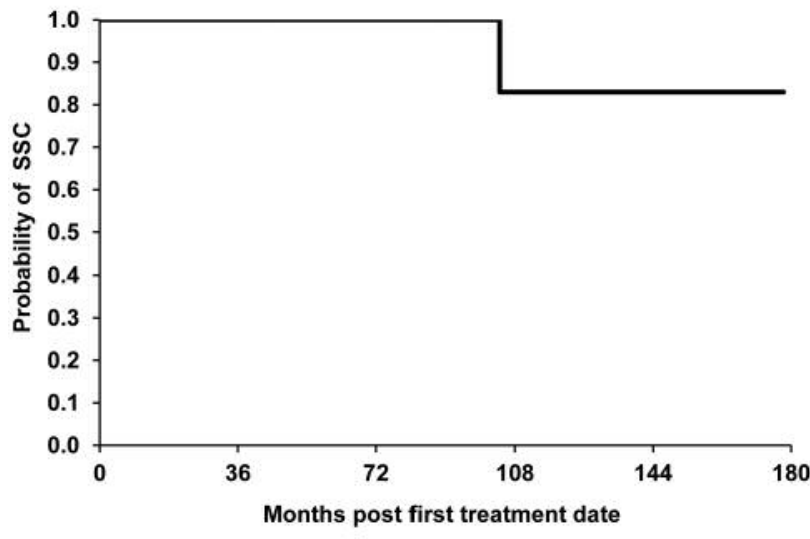

Figure 6. Probability of squamous cell carcinoma (SCC) patients with polymorphous low-grade adenocarcinoma. Median survival not calculable. 
Table II. Overall survival probabilities.

\begin{tabular}{|c|c|c|c|c|c|c|c|}
\hline \multirow[b]{3}{*}{ Overall } & \multicolumn{6}{|c|}{ CSS at } & \multirow[b]{3}{*}{$p$-Value* } \\
\hline & \multicolumn{2}{|c|}{5 Years } & \multicolumn{2}{|c|}{10 Years } & \multicolumn{2}{|c|}{15 Years } & \\
\hline & Survival probability & $95 \% \mathrm{CI}$ & Survival probability & $95 \% \mathrm{CI}$ & Survival probability & $95 \% \mathrm{CI}$ & \\
\hline MECA & 0.81 & $0.56-0.93$ & 0.68 & $0.32-0.87$ & 0.68 & $0.32-0.87$ & \\
\hline ACC & 0.67 & $0.42-0.83$ & 0.67 & $0.42-0.83$ & 0.45 & $0.10-0.76$ & $0.5046^{a}$ \\
\hline SCC & 0.63 & $0.24-0.87$ & 0.63 & $0.24-0.87$ & 0 & & $\begin{array}{l}0.0831^{\mathrm{a}} \\
0.2420^{\mathrm{b}}\end{array}$ \\
\hline PLGA & 1.00 & & 0.83 & $0.27-0.97$ & 0.83 & $0.27-0.97$ & $\begin{array}{l}0.3529^{\mathrm{a}} \\
0.0917^{\mathrm{b}} \\
0.0215^{\mathrm{c}}\end{array}$ \\
\hline
\end{tabular}

ACC: Adenoid cystic carcinoma; MECA: mucoepidermoid carcinoma; SCC: squamous cell carcinoma; PLGA: polymorphous low-grade adenocarcinoma; CI: confidence interval. *Log-rank test (between survival graphs): vs. ${ }^{\mathrm{a} M E G A}$, ${ }^{\mathrm{b}} \mathrm{ACC},{ }^{\mathrm{c} S C C}$.

induction or adjuvant setting. The response rates associated with combination therapy, most commonly cyclophosphamide, doxorubicin and cisplatin, are higher than those with a single agent (32).

Management of the N0 neck in patients with malignant salivary gland tumors is still controversial. There is a lack of consensus on the rate of cervical metastasis, which can reach $53 \%$ (33), and that of occult metastasis has been reported to be from $8 \%$ to $19 \%$ (33-36). In 2013, Herman et al. found that patients with $\mathrm{cNO}$ high-grade salivary gland carcinomas who were to undergo surgery and postoperative RT likely do not benefit from a planned neck dissection (37).

The long-term survival rate of patients with minor salivary gland malignant tumors is high. Evaluating the prognostic factors and the efficacy of treatment is more complex: $\mathrm{Li}$ et al. evaluated the treatment outcome of 103 patients with minor salivary gland carcinomas of the hard palate treated with surgery alone or with combined surgery and postoperative radiotherapy. The most common histological types were adenoid cystic carcinoma and MECA. Overall survival rates at 5 and 10 years were $77.9 \%$ and $65.7 \%$, respectively, with recurrence-free survival and CSS of $77.9 \%$. There was no significant difference in overall survival, recurrence-free survival and CSS between patients who underwent surgery alone and those who underwent surgery plus post-operative radiotherapy (38). Surgery is the primary treatment for minor salivary gland carcinoma of the hard palate. Sufficient surgical excision with adequate margins is essential for a favorable outcome. In the current study, we also noted a tendency for diversity in CSS probabilities among the different types of malignancies, especially in the long-term where patients with adenoid cystic carcinoma fared more poorly and those with PLGA fared better. This difference in CSS probabilities between these two groups of patients was highly significant. These rates at 5 years for patients with MECA, adenoid cystic carcinoma, SCC and PLGA were 0.81, 0.67, 0.63 and 1.00, respectively, while at 15 years they dropped to $0.68,0.45$, 0.63 and 0.83 , respectively (Table II). This tendency is reflected in the mortality rates as given in Table I where among the patients who died, $36.4 \%$ were diagnosed with adenoid cystic carcinoma, while only $21.5 \%$ of the surviving patients were diagnosed with this malignancy. This pattern was reversed in the case of PLGA, for which only $4.6 \%$ of patients who died had this diagnosis as compared to $10.1 \%$ of the surviving patients.

In summary, one can conclude from the currently presented data that the CSS and the DFS probabilities in salivary malignancies were quite high at 5 years $(0.69-0.83)$, higher than, for example, in oral cancer (39). However, these rates dropped over the long-term and at 15 years they reached $0.54-0.61$; this shows that in salivary gland cancer, the lethal effect of malignancy is often delayed and prolonged. Tumor histology, grade and stage certainly play a role in predicting prognosis; however, other factors such as molecular markers should be further studied for their role in an effort to improve prognosis prediction.

\section{References}

1 Pinheiro J, Sá Fernandes M, Pereira AR and Lopes JM: Histological subtypes and clinical behavior evaluation of salivary gland tumors. Acta Med Port 31: 641-647, 2018.

2 Zamani M, Grønhøj C, Schmidt Jensen J, von Buchwald C, Charabi BW and Hjuler T: Survival and characteristics of pediatric salivary gland cancer: A systematic review and metaanalysis. Pediatr Blood Cancer 2018: e27543, 2018.

3 Lombardi D, Accorona R, Lambert A, Mercante G, Coropciuc R, Paderno A, Lancini D, Spriano G, Nicolai P and Vander Poorten V: Long-term outcomes and prognosis in submandibular gland malignant tumors: A multicenter study. Laryngoscope, 2018. doi: 10.1002/lary.27236 
4 Chakrabarti S, Nair D, Malik A, Qayyumi B, Nair S, Agrawal JP and Chaturvedi P: Prognostic factors in parotid cancers: Clinicopathological and treatment factors influencing outcomes. Indian J Cancer 55: 98-104, 2018.

5 Šteiner P, Andreasen S, Grossmann P, Hauer L, Vaněček T, Miesbauerová M, Santana T, Kiss K, Slouka D and Skálová A: Prognostic significance of $1 \mathrm{p} 36$ locus deletion in adenoid cystic carcinoma of the salivary glands. Virchows Arch 473: 471-480, 2018.

6 Boon E, Valstar MH, van der Graaf WTA, Bloemena E, Willems SM, Meeuwis CA, Slootweg PJ, Smit LA, Merkx MAW, Takes RP, Kaanders JHAM, Groenen PJTA, Flucke UE and van Herpen CML: Clinicopathological characteristics and outcome of 31 patients with ETV6-NTRK3 fusion gene confirmed (mammary analogue) secretory carcinoma of salivary glands. Oral Oncol 82: 29-33, 2018.

7 Ettl T, Schwarz-Furlan S, Gosau M and Reichert TE: Salivary gland carcinomas. Oral Maxillofac Surg 16: 267-283, 2012.

8 Guzzo M, Locati LD, Prott FJ, Gatta G, McGurk M and Licitra L: Major and minor salivary gland tumors. Crit Rev Oncol Hematol 74: 134-148, 2010.

9 Gallo O, Franchi A, Bianchi S, Boddi V, Giannelli E and Alajmo E: p53 oncoprotein expression in parotid gland carcinoma is associated with clinical outcome. Cancer 75: 2037-2044, 1995.

10 Sequeiros-Santiago G, Garcia-Carracedo D, Fresno MF, Suarez C, Rodrigo JP and Gonzalez MV: Oncogene amplification pattern in adenoid cystic carcinoma of the salivary glands. Oncol Rep 21: 1215-1222, 2009.

11 Yamazaki M, Fujii S, Murata Y, Hayashi R and Ochiai A: High expression level of geminin predicts a poor clinical outcome in salivary gland carcinomas. Histopathology 56: 883-892, 2010.

12 Ettl T, Schwarz S, Kleinsasser N, Hartmann A, Reichert TE and Driemel O: Overexpression of EGFR and absence of CKIT expression correlate with poor prognosis in salivary gland carcinomas. Histopathology 53: 567-577, 2008.

13 Ettl T, Stiegler C, Zeitler K, Agaimy A, Zenk J, Reichert TE, Gosau M, Kühnel T, Brockhoff G and Schwarz S: EGFR, HER2, survivin, and loss of pSTAT3 characterize high-grade malignancy in salivary gland cancer with impact on prognosis. Hum Pathol 43: 921-931, 2012.

14 Miyabe S, Okabe M, Nagatsuka H, Hasegawa Y, Inagaki A, Ijichi K, Nagai N, Eimoto T, Yokoi M, Shimozato K and Inagaki $\mathrm{H}$ : Prognostic significance of p27KIP1, Ki-67, and CRTC1MAML2 fusion transcript in mucoepidermoid carcinoma: A molecular and clinicopathologic study of 101 cases. J Oral Maxillofac Surg 67: 1432-1441, 2009.

15 Nakayama T, Miyabe S, Okabe M, Sakuma H, Ijichi K, Hasegawa Y, Nagatsuka H, Shimozato K and Inagaki H: Clinicopathological significance of the CRTC3-MAML2 fusion transcript in mucoepidermoid carcinoma. Mod Pathol 22: 1575-1581, 2009.

16 Terhaard $\mathrm{CH}$, Lubsen $\mathrm{H}$, Van der Tweel I, Hilgers FJ, Eijkenboom WM, Marres HA, Tjho-Heslinga RE, de Jong JM, Roodenburg JL and Dutch Head and Neck Oncology Cooperative Group: Salivary gland carcinoma: independent prognostic factors for locoregional control, distant metastases and overall survival: Results of the Dutch Head and Neck Oncology Cooperative Group. Head Neck 26: 681-692, 2004.

17 Renehan AG, Gleave EN, Slevin NJ and McGurk M: Clinicopathological and treatment-related factors influencing survival in parotid cancer. Br J Cancer 80: 1296-1300, 1999.
18 Speight PM and Barrett AW: Prognostic factors in malignant tumours of the salivary glands. Br J Oral Maxillofac Surg 47: 587-593, 2009.

19 Bjorndal K, Krogdahl A, Therkildsen MH, Charabi B, Kristensen CA, Andersen E, Schytte S, Primdahl H, Johansen J, Pedersen HB, Andersen LJ and Godballe C: Salivary gland carcinoma in Denmark 1990-2005: Outcome and prognostic factors. Results of the Danish Head and Neck Cancer Group (DAHANCA). Oral Oncol 48: 179-185, 2012.

20 Sultan I, Rodriguez-Galindo C, Al-Sharabati S, Guzzo M, Casanova $\mathrm{M}$ and Ferrari A: Salivary gland carcinomas in children and adolescents: A population-based study, with comparison to adult cases. Head Neck 33: 1476-1481, 2011.

21 Kupferman ME, de la Garza GO, Santillan AA, Williams MD, Varghese BT, Huh W, Roberts D and Weber RS: Outcomes of pediatric patients with malignancies of the major salivary glands. Ann Surg Oncol 17: 3301-3307, 2010.

22 Jeannon JP, Calman F, Gleeson M, McGurk M, Morgan P, O'Connell M, Odell E and Simo R: Management of advanced parotid cancer. A systematic review. Eur J Surg Oncol 35: 908915, 2009.

23 Spiro RH: Factors affecting survival in salivary gland cancers. In: Controversies in the Management of Salivary Gland Disease. McGurk M and Renehan A (eds.). Oxford, Oxford University Press., pp. 143-150, 2001.

24 Speight PM and Barrett AW: Prognostic factors in malignant tumours of the salivary glands. Br J Oral Maxillofac Surg 47: 587-593, 2009

25 McGurk M: Management of salivary gland cancer: Clinically or pathologically based? Overview. In: Controversies in the Management of Salivary Gland Disease. McGurk M and Renehan A (eds.) Oxford, Oxford University Press, pp. 155-161, 2001.

26 Vander Poorten VL, Balm AJ, Hilgers FJ, Tan IB, Keus RB and Hart AA: Stage as major long term outcome predictor in minor salivary gland carcinoma. Cancer 89: 1195-204, 2000.

27 Slevin N and Frankenthaler R: The role of radiotherapy in the management of salivary gland cancer. In: Controversies in the Management of Salivary Gland Disease. McGurk M and Renehan A (eds.). Oxford, Oxford University Press., pp. 163$172,2001$.

28 Bjørndal K, Krogdahl A, Therkildsen MH, Overgaard J, Johansen J, Kristensen CA, Homøe P, Sørensen CH, Andersen E, Bundgaard T, Primdahl H,Lambertsen K, Andersen LJ and Godballe C: Salivary gland carcinoma in Denmark 1990-2005: A national study of incidence, site and histology. Results of the Danish Head and Neck Cancer Group (DAHANCA). Oral Oncol 47: 677-682, 2011.

29 Seethala RR: Salivary gland tumors: Current concepts and controversies. Surg Pathol Clin 10: 155-176, 2017.

30 Carlson ER and Schlieve T: Salivary gland malignancies. Oral Maxillofac Surg Clin North Am 31: 125-144, 2019.

31 Bell RB, Dierks EJ, Homer L and Potter BE: Management and outcome of patients with malignant salivary gland tumors. J Oral Maxillofac Surg 63: 917-928, 2005.

32 Posner MR, Ervin TJ, Weichselbaum RR, Fabian RL and Miller D: Chemotherapy of advanced salivary gland neoplasms. Cancer 50: 2261-2264, 1982.

33 Stennert E, Kisner D, Jungehuelsing M, Guntinas-Lichius O, Schröder U, Eckel HE and Klussmann JP: High incidence of 
lymph node metastasis in major salivary gland cancer. Arch Otolaryngol Head Neck Surg 129: 720-723, 2003.

34 Stenner M, Molls C, Luers JC, Beutner D, Klussmann JP and Huettenbrink KB: Occurrence of lymph node metastasis in earlystage parotid gland cancer. Eur Arch Otorhinolaryngol 269: 643$648,2012$.

35 Rodríguez-Cuevas S, Labastida S, Baena L and Gallegos F: Risk of nodal metastases from malignant salivary gland tumors related to tumor size and grade of malignancy. Eur Arch Otorhinolaryngol 252: 139-142, 1995.

36 Korkmaz H, Yoo GH, Du W, Hocwald E, Otero-Garcia JE, Volkan Adsay N, Shibuya T and Jacobs JR: Predictors of nodal metastasis in salivary gland cancer. J Surg Oncol 80: 186-189, 2002.

37 Herman MP, Werning JW, Morris CG, Kirwan JM, Amdur RJ, and Mendenhall WM: Elective neck management for high-grade salivary gland carcinoma. Am J Otolaryngol 34: 205-208, 2013.
38 Li Q, Zhang XR, Liu XK, Liu ZM, Liu WW, Li H and Guo ZM: Long-term treatment outcome of minor salivary gland carcinoma of the hard palate. Oral Oncology 48: 456-462, 2012.

39 Nagler RM, Kerner H, Laufer D, Ben-Eliezer S, Minkov I and Ben-Itzhak O: Squamous cell carcinoma of the tongue: the prevalence and prognostic roles of p53, BCL-2, c-ERBB-2 and apoptotic rate as related to clinical and pathological characteristics in a retrospective study. Cancer Lett 186: 137-150, 2002.

Received December 10, 2018

Revised December 27, 2018

Accepted January 10, 2019 